\title{
In Vivo Evaluation of Vena Caval Filters: Can Function Be Linked to Design Characteristics?
}

\author{
Mary C. Proctor, ${ }^{1}$ Kyung J. Cho, ${ }^{2}$ Lazar J. Greenfield ${ }^{1}$ \\ ${ }^{1}$ Department of Surgery, University of Michigan Hospitals, 1500 East Medical Center Drive, Ann Arbor, MI 48109-0346, USA \\ ${ }^{2}$ Department of Radiology, University of Michigan Hospitals, 1500 East Medical Center Drive, Ann Arbor, MI 48109-0346, USA
}

\begin{abstract}
Purpose: To compare the five vena caval filters marketed in the United States and one investigational vena caval filter and to determine whether there is an association between their design and their in vivo function.

Methods: Four of each type of filter-Simon Nitinol (SN), Bird's Nest (BN), Vena Tech (VT), Greenfield stainless steel (PSGF), Greenfield titanium (TGF), and the investigational stent cone filter (NGF) - were studied for 60 days in 12 sheep. Radiographic and pathologic outcomes to be assessed included clot capture and resolution, vena caval penetration, position of the filter, thrombogenicity, and vessel wall reaction.

Results: Filters differed with respect to the number of clottrapping levels and the interdependence of the legs. All devices were successfully placed. Intentionally embolized clot was captured. One VT and two SN filters migrated in response to clot capture. Resolution of thrombus was variable, and related to the design of the device. Fibrin webbing was widely present with the VT, BN, and SN filters but limited in the others. The VT and NGF filters demonstrated the most stable filter base diameter.

Conclusions: The performance of vena caval filters differs with respect to clot resolution and mechanical stability. Interdependent filter limbs and single-stage conical capture sites appear to result in more favorable performance in in vivo studies.
\end{abstract}

Key words: Animal study-Design-PerformanceThrombus resolution-Vena cava filter

An ideal vena caval filter must combine the ability to capture clinically significant emboli while maintaining the patency of the vena cava. In addition, it must be mechanically stable. An investigational filter has been developed by the Boston

Correspondence to: M.C. Proctor, M.S., Department of Surgery, University of Michigan Hospitals, 2101 Taubman Center/Box 0346, Ann Arbor, MI 48109-0346, USA
Scientific Vascular Division (BSC, Natick, MA, USA) and in this study we compared it with the filters currently approved for the US market to determine the extent to which it meets these criteria (Table 1).

The investigational "stent cone" filter, referred to as the NGF, has a unique design incorporating the traditional Greenfield cone combined with a stent base. It is manufactured of nitinol wire to allow compression into a $9 \mathrm{Fr}$ delivery system. The cone portion of the NGF is comparable in volume to the original Greenfield filter. At $55 \mathrm{~mm}$ it is the longest of the BSC filters. Its 32-mm resting base diameter is similar to the titanium Greenfield filter (TGF) at $38 \mathrm{~mm}$ and the percutaneous stainless steel Greenfield filter (PSGF) at $32 \mathrm{~mm}$ (Fig. 1). Our purpose was to compare performance with respect to clot capture, clot resolution, thrombogenicity, migration, filter stability, and histologic effects on the vena cava.

\section{Materials and Methods}

The study was conducted in the Greenfield Vascular Research Laboratory under approval by the University Committee on the Use and Care of Animals and according to Federal regulations. The six devices included the Bird's Nest filter (BN; Cook, Bloomington, IN, USA), the Greenfield filters (PSGF, TGF, NGF, Boston Scientific/Meditech, Natick, MA, USA), the Simon Nitinol filter (SN; Bard, Boston, MA, USA) and the VenaTech filter (VT; Braun, Evanston, IL, USA). Two devices of each type were placed in each of 12 sheep weighing at least $34 \mathrm{~kg}$, one above and one below the renal vein according to the matrix in Table 2 . All were placed via the right femoral vein using a prototype 9 Fr transit delivery system.

Plain films and cavograms with intravenous contrast were obtained in the anteroposterior and lateral projections both prior to and following filter placement, following intentional embolization and just prior to necropsy. Autologous clot for embolization was produced by adding thrombin to $20 \mathrm{ml}$ of blood drawn from each animal. The blood was placed in a $35-\mathrm{cm} \times 9$-mm-diameter tube and aged for $24 \mathrm{hr}$. Five grams of clots were divided into 100$\mathrm{mm} \times 9$-mm segments and released into the femoral vein of six animals via a $50-\mathrm{ml}$ syringe with a modified tip inserted through a femoral venotomy (Table 2) at the time of filter placement. Move- 
Table 1. The study devices and their major design characteristics

\begin{tabular}{llll}
\hline Device & Abbreviation & $\begin{array}{l}\text { Trapping } \\
\text { level(s) }\end{array}$ & $\begin{array}{l}\text { Filter leg } \\
\text { attachment }\end{array}$ \\
\hline $\begin{array}{l}\text { Percutaneous Stainless Steel } \\
\text { Greenfield (Boston } \\
\quad \text { Scientific) }\end{array}$ & PSGF & Single & Independent \\
$\begin{array}{c}\text { Titanium Greenfield } \\
\quad \text { Boston Scientific) }\end{array}$ & TGF & Single & Independent \\
$\begin{array}{l}\text { Next Generation (Boston } \\
\quad \text { Scientific) }\end{array}$ & NGF & Single & Dependent \\
$\begin{array}{l}\text { Bird's Nest (Cook) } \\
\text { Simon Nitinol (Bard) }\end{array}$ & BN & Multiple & Independent \\
VenaTech (B. Braun) & VT & $\begin{array}{l}\text { Dual } \\
\text { Single }\end{array}$ & $\begin{array}{l}\text { Independent } \\
\text { Dependent }\end{array}$ \\
\hline
\end{tabular}

${ }^{a}$ See Materials and Methods
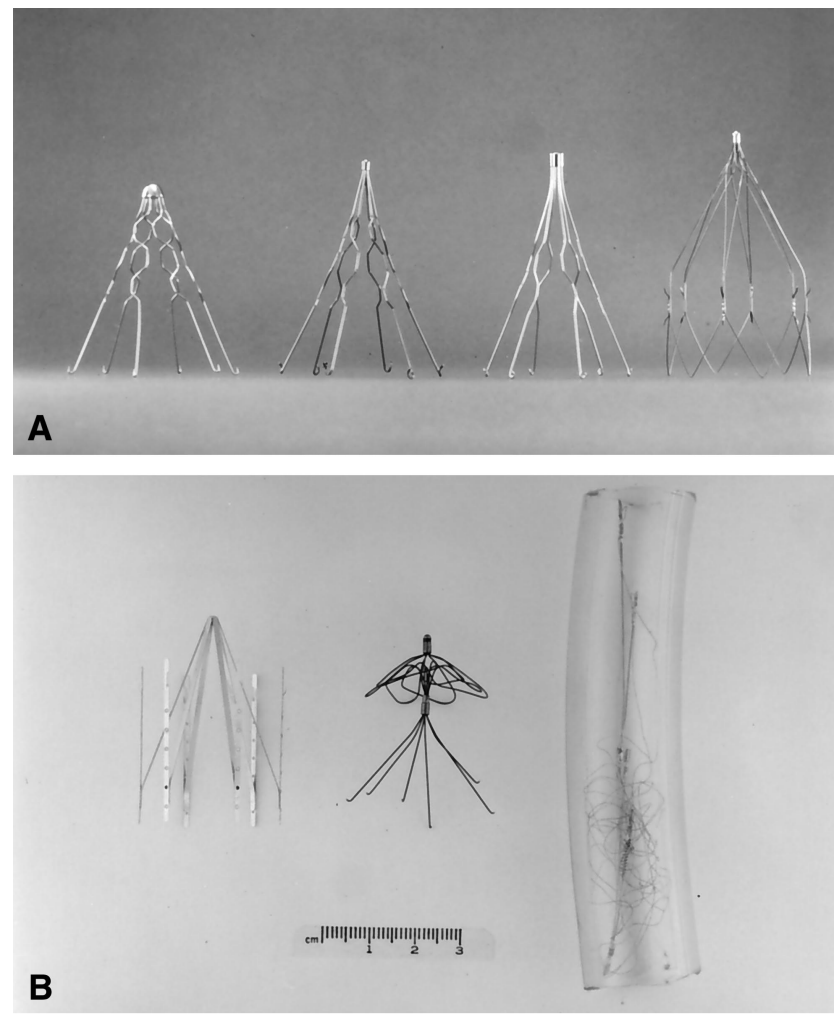

Fig. 1. A The three traditional Greenfield filters: original stainless steel (left), titanium (center), percutaneous steel (right), and the investigational device (far right) which combines the advantages of a cone with the reduced delivery profile. B The Vena Tech (left), Simon Nitinol (center) and Bird's Nest (right) filters marketed in the United States.

ment of the filter during clot challenge was observed under fluoroscopy and measured from post-capture plain films. The animals were recovered and returned to the housing facility for a 60-day survival period. At necropsy, the vena cavas were perfusion-fixed with formalin. After explant, they were photographed from a lateral, cranial and caudal aspect, then opened lengthwise. All filters were examined by a pathologist who was responsible for characterizing thrombus, caval penetration by filter components, filter leg
Table 2. Study design for placement and clot challenge: study design matrix with type of filter location and whether it underwent intentional clot embolization. In each animal, a Boston Scientific device was paired with another marketed device

\begin{tabular}{cll}
\hline Filter & Location $^{a}$ & $\begin{array}{l}\text { Intentionally } \\
\text { embolized }\end{array}$ \\
\hline 1 NGF & IR & Yes \\
VT & SR & No \\
2 NGF & IR & No \\
SN & SR & No \\
3 PSGF & IR & Yes \\
BN & SR & No \\
4 PSGF & IR & No \\
VT & SR & No \\
5 TGF & IR & Yes \\
SN & SR & No \\
6 TGF & IR & No \\
BN & SR & No \\
7 VT & IR & Yes \\
TGF & SR & No \\
8 VT & IR & No \\
PSGF & SR & No \\
SN & IR & Yes \\
NGF & SR & No \\
10 SN & IR & No \\
TGF & SR & No \\
BN & IR & Yes \\
PSGF & SR & No \\
BN & IR & No \\
NGF & SR & No \\
\hline
\end{tabular}

${ }^{a} \mathrm{IR}=$ infrarenal; $\mathrm{SR}=$ suprarenal

distribution, and fixation site tissue reaction. Histology samples were prepared of tissue found at the fixation site and trapped on or within the filter.

The BN filter differs from the others in that it is free-formed continuous wire without a defined shape. For this reason, we did not include it in assessments of centering or symmetry.

Filter leg attachment was characterized as being independent if the legs were free of one another, while dependent indicated a physical connection in such a manner that movement of one leg resulted in movement of the others (Table 1). Criteria for determining clinically important movement were based on standards accepted by the US Food and Drug Administration (FDA) in the 1995 Greenfield Stainless Steel Filter marketing approval submission and included longitudinal movement $>20 \mathrm{~mm}$ or filter base increase $>7 \mathrm{~mm}$.

Data were entered into case reporting forms and analyzed using Systat 5.1 (Systat, Evanston, IL, USA). The study was designed to identify large differences among the devices. Due to the small sample size, nonparametric tests were used to analyze continuous variables while likelihood ratio chi-squares or Fisher's Exact test were used with dichotomous data. A nonparametric ANOVA was performed initially to determine whether there were differences among the devices. When significant, further comparisons were done to identify the direction of the differences.

\section{Results}

Animals were comparable in weight $(48-52 \mathrm{~kg})$ and caval diameter $(17-20 \mathrm{~mm})(p>0.05)$, thus avoiding potential 

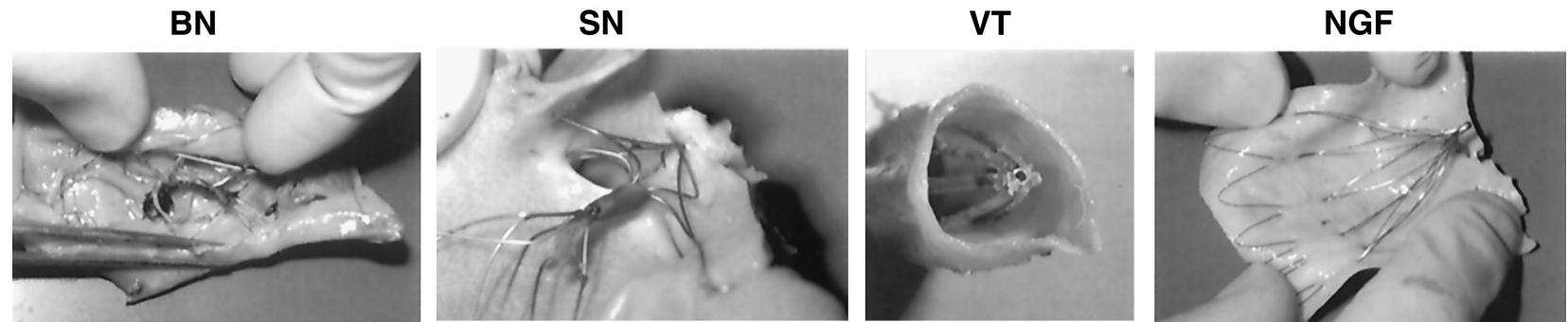

Fig. 2. Clot is seen under the wire of the BN filter and around the spindle of the SN filter. There is clot debris on the struts of the VT filter and a small clot at the apex of the NGF.

bias. All filters were successfully placed according to the manufacturer's directions.

\section{Clot Capture, Thrombogenicity, and Resolution}

Each of the challenged filters trapped all the autologous emboli while maintaining vena cava flow. There was proximal movement of an infrarenal VT and SN filter of $9 \mathrm{~mm}$ and $5 \mathrm{~mm}$ respectively in response to the challenge as observed under fluoroscopy and measured from pre- and post-challenge plain films. Thrombus resolution was evaluated by venacavography and visual inspection at 60 days Residual clot was found in two SN, one $\mathrm{BN}$, one NGF, and one TGF filters ( $p=0.58)$ (Fig. 2). In all but two cases, the pathologist characterized the thrombus as post-mortem due to its lack of organization. However, two SN filters had pathologic evidence of organized thrombus, one of which had been challenged with autologous clot and one formed spontaneously.

\section{Filter Position and Stability}

Centering of the filter within the vena cava was determined from cavograms, on the basis of the relationship between the apex of the filter and walls of the vena cava. The VT filter demonstrated the most optimal centering based on the cavograms. Symmetric distribution of the filter legs was determined in two ways: contrast venacavography and actual measurement of inter-leg spacing of specimens obtained at necropsy. Following placement, there was a difference among the devices with respect to the leg distribution, with the NGF having the poorest performance $(p=0.014)$. However, at explant, the filter legs were well distributed and we failed to find differences among devices by either measurement technique $(p=0.09)$.

The PSGF, NGF, and VT filters demonstrated the greatest overall resistance to movement. Table 3 demonstrates the mean movement, which was not statistically different among filters. We also measured changes in base diameter of the filters and failed to find a statistical difference $(p=0.07)$. However, there was a trend favoring the NGF $(1.7 \mathrm{~mm})$ while the $\mathrm{BN}$ filter had the greatest change $(7.3 \mathrm{~mm})$. One characteristic of the $\mathrm{BN}$ device not previously reported is the possible distortion it causes to the vena cava. Figure 3
Table 3. Summary of mean movement of filters documented over a 60-day observation period (direction not considered)

\begin{tabular}{lclc}
\hline Filter & $\begin{array}{l}\text { Mean (SD) } \\
\text { movement }(\mathrm{mm})^{a}\end{array}$ & $\begin{array}{l}\text { Mean (SD) filter } \\
\text { base change (mm) }\end{array}$ & $\begin{array}{l}\text { Mean (SD) intraleg } \\
\text { distance (mm) }\end{array}$ \\
\hline SN & $9(16.9)$ & $4.3(3.8)$ & $3.8(2.2)$ \\
VT & $4(4.1)$ & $1.7(1.1)$ & $5.5(3)$ \\
BN & $12(16.4)$ & $7.3(3.2)$ & N/A \\
NGF & $1(2.7)$ & $1.7(1.3)$ & $4.3(1.9)$ \\
PSGF & $1(1.4)$ & $4(4.2)$ & $5.86(3.8)$ \\
TGF & $20(17.9)$ & $4.4(0.5)$ & $5.3(3.5)$ \\
\hline
\end{tabular}

${ }^{a}$ Movement less than $21 \mathrm{~mm}$ is considered to be clinically insignificant

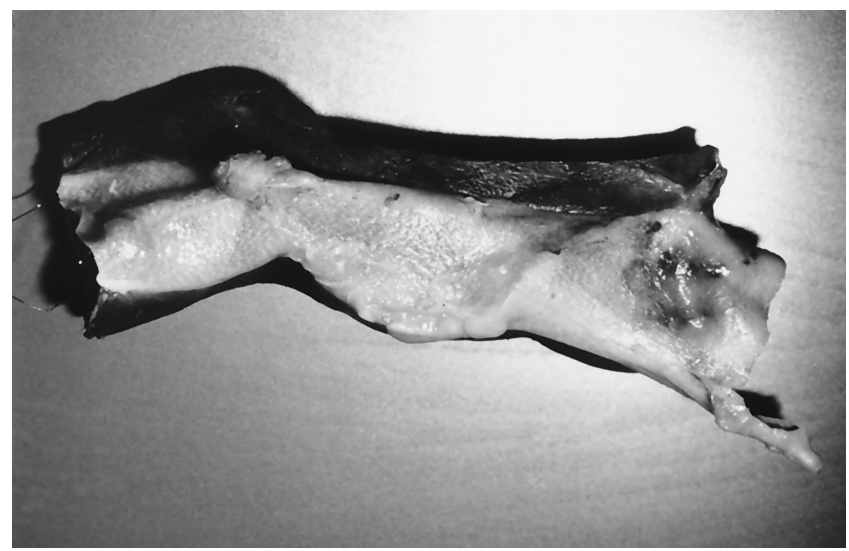

Fig. 3. The wires of the BN filter appear to distort the vena cava.

demonstrates the manner in which it twists the cava as it becomes incorporated in the wall.

\section{Pathology and Histology}

Examination of the apex of each filter demonstrated a variable degree of fibrin covering (Fig. 4) which was confirmed by the pathologist. The amount varied with the design of the device and was increased when the apex was in direct contact with the vessel wall. The effect of attachment of the filter to the vessel wall differed among devices. The VT and NGF filters were associated with the least disruption to the external surface of the cava (Fig. 5) while the hooks of the PSGF, TGF, SN, and BN filters had various degrees of externalization [1]. The cava frequently appeared to be "tent- 


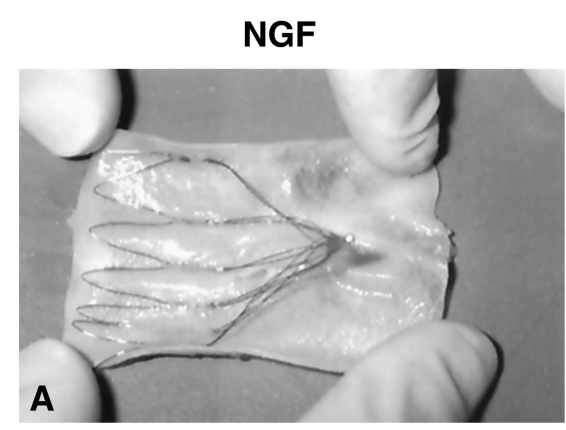

BN

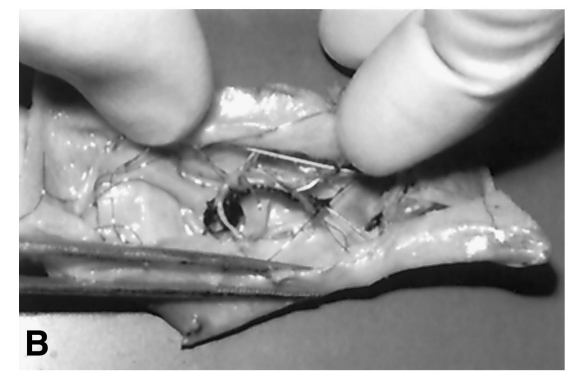

PSGF

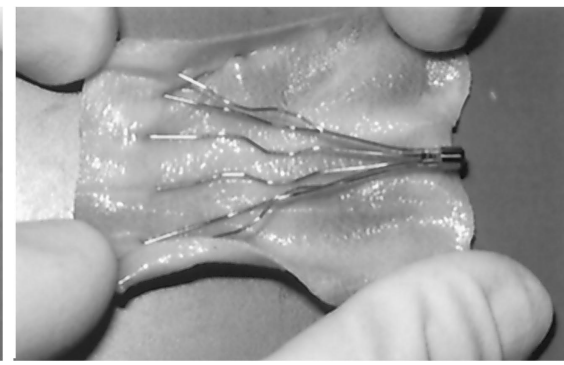

SN

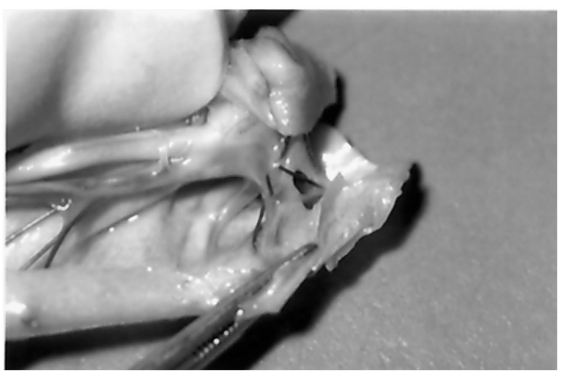

TGF

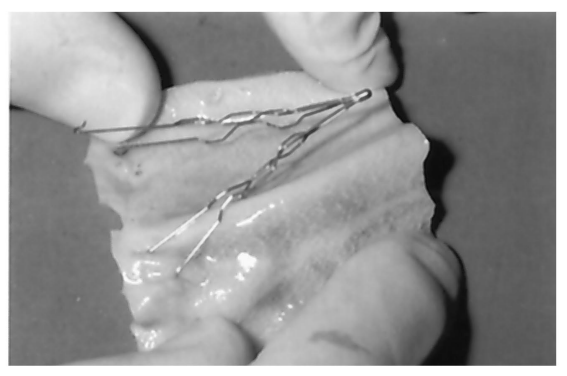

VT

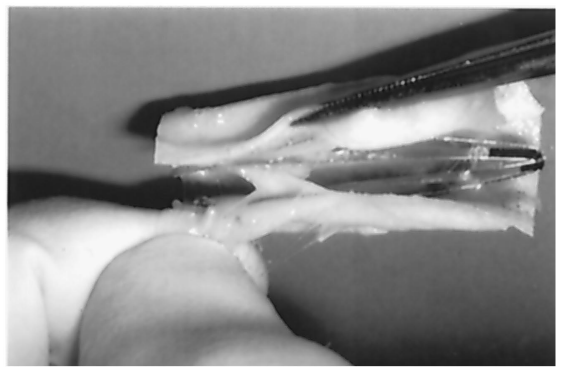

Fig. 4. A fibrin cap develops at the apex in most cases. Note the limited film on the NGF, PSGF, TGF, and VT filters as compared with the heavy layering of the $\mathrm{SN}$ and $\mathrm{BN}$ filters.

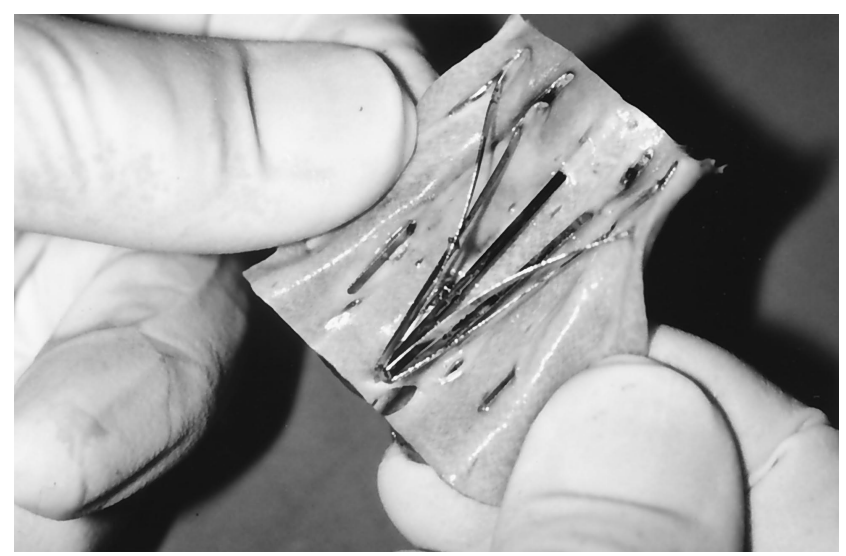

Fig. 5. The dependent legs and short hooks of the VT filter limit caval penetration.

ed" in response to radial force. If a hook penetrated slowly it became encapsulated in a fibrous nodule which protected adjacent tissue, as we have previously reported [2]. Often, the caval wall stretched behind the independent filter limbs and enclosed them, which also provided protection to external organs. In these cases, the measured filter base diameter increased but the true caval diameter remained unchanged.

\section{Discussion}

The similarity of vena caval filters is frequently suggested [3-5]. The SN and VT devices even obtained FDA approval based on inferred equivalence to the Greenfield filters during a $510 \mathrm{~K}$ approval process. This prospective in vivo study suggests that this may not be true in all areas. All the devices were successfully deployed and captured clinically significant emboli. However, the VT and SN filters moved following clot capture. This tendency may result in clinical sequelae if the final resting place is inappropriate [6-10]. Cavograms obtained immediately prior to necropsy failed to show any retained clot. However, at necropsy, several filters had clot in various stages of resolution and the extent of fibrin deposition in response to resolution differed significantly (Fig. 6). The higher rates of filter and caval occlusion reported in the literature with the VT and SN filters may be related to fibrin webbing, the extent of which can limit caval blood flow [11, 12]. It is unclear whether a filter needs to be perfectly centered within the vena cava to be effective [13], but with respect to this criterion, the NGF and VT filters were the most consistently centered. These devices share the design characteristic of inter-leg dependence: movement of one leg results in movement of one or more of the others but also limits the total amount of movement that can occur. The fixed base appears to promote centering as well as limiting caval penetration.

Changes in filter base diameter are frequently used as a surrogate for caval penetration. Devices with independent legs (PSGF, TGF, SN, BN) tended to have greater variability than did the VT and NGF filters, whose diameters are fixed by design. We were unable to correlate actual caval penetration found at necropsy with change in filter base diameter based on radiographs. Figure 7 depicts why the filter base measurement overestimates the actual change in caval diameter based on cavograms. The NGF and VT filters were also associated with the least disruption to the wall of the vena 
BN

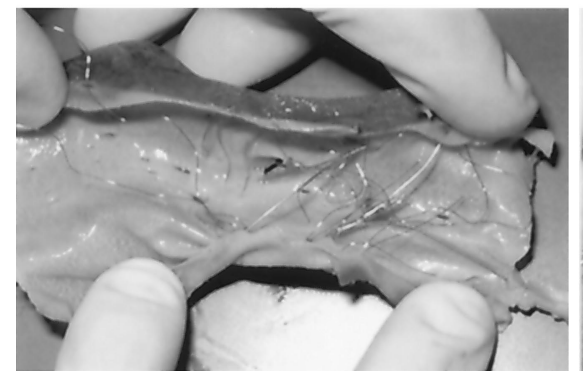

SN

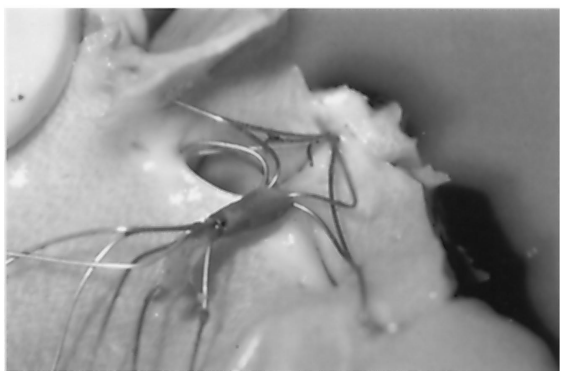

VT

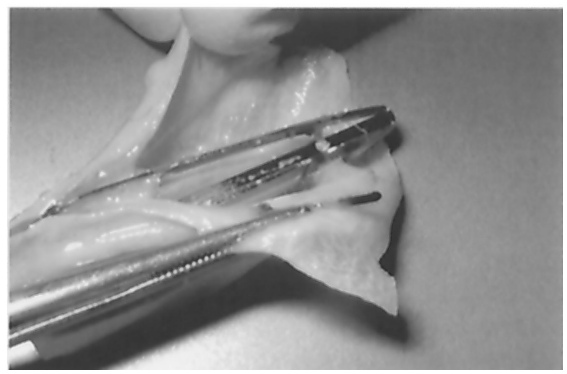

Fig. 6. The clean wires of the BN filter are a contrast to the resolving thrombus of the SN and the advanced fibrin webbing of the VT filters.

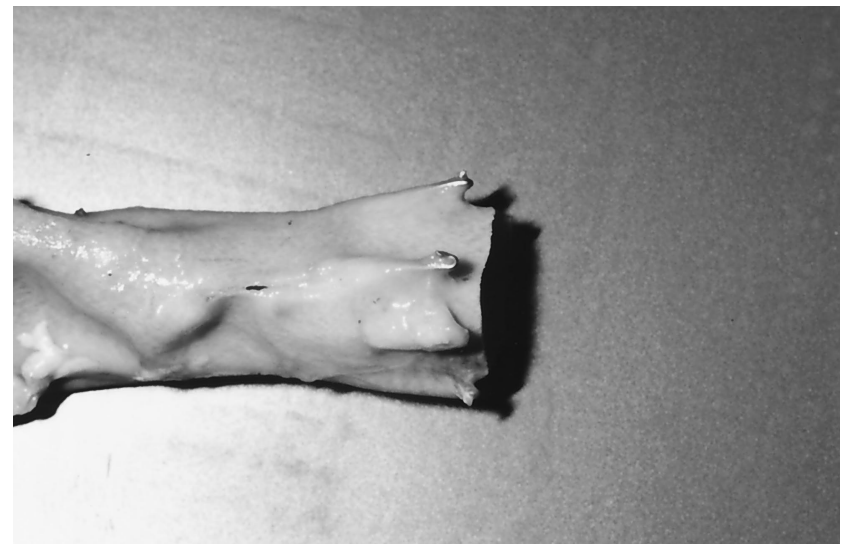

Fig. 7. Necropsy specimens increase our understanding of how filter limbs are distributed and point out the weakness of reliance on plain radiographs.

cava. These designs involve less intrusive attachment points with greater reliance on radial force resulting in a more stable diameter. We did note a tendency for the base of the VT filter to pull away from the caval wall toward the center of the cava as has previously been demonstrated [14, 15] (Fig. 5). At the other extreme, the tip on the apex of two SN filters had penetrated through the caval wall and a third caused extreme tenting. Tilting of the second clot-trapping level appeared to be responsible as it forced the apex tip through the wall.

The significance of symmetric deployment of the filter legs is discussed frequently [16-19]. Determination of leg distribution at necropsy was much more informative than radiographic images, which failed to account for the shape of the vena cava and did not predict whether the cava was well protected. The NGF had the highest incidence of asymmetry at placement, but at explant and at necropsy there was no difference among the devices. This may be due to the characteristics of nitinol that favor its original configuration and is not unlike the response we have seen with the titanium filter. It may also signify early adjustment to the shape of a vena cava that is not perfectly oval.

The gross pathologic examination showed other differences among the devices not previously reported. Both the
$\mathrm{SN}$ and $\mathrm{BN}$ filters are designed with more than one level for clot capture. When these devices trap an embolus, it is often in contact with the vessel wall and, as resolution takes place, significant fibrin disposition develops. In the single-level devices (PSGF, TGF, NGF), thrombus is held in the apex allowing circumferential flow and increased resolution with little webbing as the thrombus is not in contact with the vessel wall. In vitro flow studies by Couch et al [20] have provided an explanation for this effect. They found that the design of a filter significantly affects flow velocity and wall shear stress. A broad blunt face with near-wall contact leads to reduced near-wall velocities and wall stress which can increase the risk for thrombogenesis and vena caval occlusion. They concluded that a centered cone provides optimal flow.

In conclusion, vena caval filters differ with respect to performance characteristics in this in vivo study. Our study suggests that two design characteristics are associated with these differences: the interdependence of the leg attachment and the number of clot-trapping levels. The investigational filter incorporates a single level of apical clot trapping in addition to a stent base which limits change in filter base diameter. Its smaller attachment points result in less disruption of the caval wall. Unlike the VT filter with a cone apex and stabilizing leg, the stent base reduces flow disturbance within the vena cava, which reduces the risk of caval occlusion. By relating experience with existing filter devices to their design characteristics, new devices can be developed that are closer to "ideal".

Acknowledgment. Laboratory support was provided by Boston Scientific Corporation.

\section{References}

1. McCowan TC, Ferris EJ, Carver DK, Molpus WM (1992) Complications of the nitinol vena caval filter. J Vasc Interv Radiol 3:401-408

2. Proctor MC, Greenfield LJ (1997) Apparent vena caval penetration by the Greenfield filter. J Vasc Interv Radiol 8:196-197

3. Ferris E, McCowan T, Carver DK, McFarland DR (1993) Percutaneous inferior vena caval filters: Follow-up of seven designs in 320 patients. Radiology 188:851-856

4. Grassi CJ (1991) Inferior vena caval filters: Analysis of five currently available devices. AJR 156:813-821

5. Mohan CR, Hoballah JJ, Sharp WJ, Kresowik T, Lu CT, Corson JD 
(1995) Comparative efficacy and complications of vena caval filters. J Vasc Surg 21:235-246

6. LaPlante J, Contractor F, Kiproff P, Khoury M (1993) Migration of the Simon Nitinol vena cava filter to the chest. AJR 160:385-386

7. Queriroz R, Waldman DL (1998) Transvenous retrieval of a Greenfield filter lodged in the tricuspid valve. Cathet Cardiovasc Diagn 44:310 312

8. Salamipour H, Rivitz SM, Kaufman JA (1996) Percutaneous transfemoral retrieval of a partially deployed Simon-nitinol filter misplaced into the ascending lumbar vein. J Vasc Interv Radiol 7:917-919

9. Shlansky-Goldberg RD, Wing CM, Leveen RF, Cope C (1993) Effectiveness of a prolapsed Bird's Nest Filter. J Vasc Interv Radiol 4:505511

10. White KE, McLean GK (1996) Bird's Nest filter: Inferior strut migration during massive thromboembolization. J Vasc Interv Radiol 7:537540

11. Crochet DP, Brunel P, Trogrlic S, Grossetete R, Auget JL, Dary C (1999) Long-term follow-up of vena tech-LGM filter: Predictors and frequency of caval occlusion. J Vasc Interv Radiol 10:137-142

12. Grassi CJ, Matsumoto AH, Teitelbaum GP (1992) Vena caval occlusion after Simon Nitinol filter placement: Identification with MR imaging in patients with malignancy. J Vasc Interv Radiol 3:535-539

13. Kinney TB, Rose SC, Weingarten KE, Valji K, Oglevie SB, Roberts
AC (1997) IVC filter tilt and asymmetry: Comparison of the over-thewire stainless-steel and titanium Greenfield IVC filters. J Vasc Interv Radiol 8:1029-1038

14. Crochet DP, Bach-Lijour B, Grossetete R, Raffin T, Nguyen JM, Hurtrel M, Dalulsi G, LeNihouannen JC (1997) Caval incorporation of the LGM Vena Tech filter: An experimental study. J Vasc Interv Radiol $8: 419-425$

15. Dupin N, Meyer G, Diehl JL (1992) Late total closure and caudal migration of an LGM caval filter. (letter) AJR 159:1349

16. Dorfman GS (1993) Risks and benefits of manipulation of the Titanium Greenfield inferior vena cava filter after deployment: Filter facts and filter fantasies. J Vasc Interv Radiol 4:617-620

17. Greenfield LJ, Proctor MC (1992) Experimental embolic capture by asymmetric Greenfield filters. J Vasc Surg 16:436-444

18. Greenfield LJ, Proctor MC, Cho KJ, Wakefield TW (1997) Limb asymmetry in titanium Greenfield filters: Clinically significant? J Vasc Surg 26:770-775

19. Kinney TB (1998) Regarding "Limb asymmetry in titanium Greenfield filters: Clinically significant?" J Vasc Surg 27:1193-1194

20. Couch GG, Kim H, Ojha M (1997) In vitro assessment of the hemodynamic effects of a partial occlusion in a vena cava filter. J Vasc Surg 25:663-672 